\title{
NOTES
}

\section{Thermal Studies of Solution Epoxidized trans-1,4-Polyisoprene}

\author{
Nadarajah VASANTHAN* \\ Department of Chemistry, City College, New York, NY 10031, U.S.A.
}

(Received March 22, 1994)

\begin{abstract}
KEY WORDS trans-1,4-Polyisoprene / Comonomer / Differential Scanning
Calorimetry / Heat of Fusion / Melting Temperature /
\end{abstract}

When a small amount of comonomer units is introduced into a linear homopolymer, one obtains a copolymer which still crystallizes into a semicrystalline structure resembling that of the homopolymer. A large number of experiments were carried out in the past to determine the role of comonomer units in crystallization, annealing and melting. Roe and Greniwiski ${ }^{1}$ studied the effects of chlorination on the crystallization of polyethylene. They found that as the concentrations of $\mathrm{C} 1$ atoms along the back bone become larger, the ' $a$ ' dimension of the for polyethylene unit cell increases. This behavior was attributed to greater levels of $\mathrm{Cl}$ incorporation into the crystalline phase of polyethylene. This trend was consistent with their experimental determined heat of fusion values. Heat of fusion $\left(\Delta H_{\mathrm{f}}\right)$ was observed to decrease as the degree of chlorination increased.

Several workers have studied model copolymer systems to determine the effects of primarily excluded comonomer units on observed structural data. These materials were prepared by chemically modifying the fold surface of single crystals held in suspension. Harrison and Baer $^{2,3}$ studied single crystals of polyethylene that were halogenated in suspension. Results obtained from kinetic, thermal, and infrared studies indicated that the halogenation reaction was selective to the fold surface of the crystals. No changes were observed in the $\Delta H_{\mathrm{f}}$ values for each of the halogenated crystals. However after these crystals melted and recrystallized, a significant drop in $\Delta H_{\mathrm{f}}$ was observed. Similar behavior was observed by Marchatti and Martuscelli $^{4}$ for single crystals of polybutadiene brominated in suspension.

Crystallization of trans-1,4-polybutadiene containing up to $10 \%$ cis units was carried out by Wang and Woodward. ${ }^{5}$ They showed that most of the cis units are rejected from the crystal core. Recently, the crystallization of segmented block copolymer prepared by surface hydrochlorination and epoxidation of solution crystallized trans-1,4-polyisoprene (TPI) lamellas were carried out from 2-octanol, 2-pentanol, and 2-pentanone. ${ }^{6,7}$ The resulting precipitates were studied by SEM, DSC, and FTIR and in some cases by the suspension epoxidation/C-13 NMR method. It was shown that there is no incorporation of modified TPI in the crystal core. The crystallization of TPI and solution epoxidized TPI has been studied recently using FTIR spectroscopy. ${ }^{8}$ In this study effect of oxirane content and crystallization temperature on amorphous fraction were followed.

* Present address: Fiber and Polymer Science, College of Textiles, Campas Box 8301, North Carolina State Univeersity, Raleigh, NC 27695-8301, U.S.A. 
In the work to be presented in this note the melt crystallization of three epoxidized trans1,4-polyisoprene was studied using differential scanning calorimetry. The dependence of melting temperature on the amount of epoxidation and the crystallization temperature is discussed.

\section{EXPERIMENTAL}

\section{Samples}

Three samples of solution epoxidized trans1,4-polyisoprene were used in this study. The three copolymers were prepared previously by reaction with $m$-chloroperbenzoic acid in chloroform solution using unfractionated polymer having $M_{w}=1.7 \times 10^{5}$ and $M_{w} / M_{n}=$ 4.8. The oxirane contents were determined to be $2.2,5,9.8 \mathrm{~mol} \%$.

\section{Crystallization}

Bulk crystallization was carried out using solution crystallized mats of epoxidized TPI. The mats were heated for one hour at $60^{\circ} \mathrm{C}$ on a glass plate, and then the temperature was reduced to desired crystallization temperature at 25 and $36^{\circ} \mathrm{C}$.

\section{DSC Measurements}

Melting temperature for all samples were obtained with a Du Pont 1090 thermal analyzer at a heating rate of $10^{\circ} \mathrm{C} \mathrm{min}-1$.

\section{RESULTS AND DISCUSSION}

In this study oxirane units were placed in the TPI chain in amounts of 2.2, 5.0, and 9.8\% and the polymers were crystallized from the melt using the method given in Experimental section. The beta crystal form was evident from FTIR spectroscopy. The melting temperature of solution epoxidized TPI copolymers crystallized from the melt depends on the crystallization temperature $\left(T_{\mathrm{c}}\right)$ and the amount of oxirane content.

The DSC scans were obtained for 2.2, 5,
9.8\% solution epoxidized TPI as well as pure TPI samples crystallized from the melt at 25 and $36^{\circ} \mathrm{C}$. Melting temperatures were obtained by extrapolation the left hand side of the endotherm to the base line. Upon increase in oxirane content, it was apparent that endotherm become broader, onset point shifts to a lower temperature at particular $T_{\mathrm{c}}$. Melting temperatures are listed in Table I. The values given are an average of three determinations; the precession is 0.01 degrees. Melting temperatures are plotted versus epoxidation amount in Figure 1 for samples crystallized at 25 and $36^{\circ} \mathrm{C}$. The melting temperature decreases with epoxy content and increases with crystallization temperature. The melting temperature increase with an increase in $T_{\mathrm{c}}$ can be correlated

Table I.

\begin{tabular}{lcc}
\hline Mole\% epoxidation & $T_{\mathrm{c}} /{ }^{\circ} \mathrm{C}$ & $T_{\mathbf{m}} /{ }^{\circ} \mathrm{C}$ \\
\hline 0 & 25 & 37 \\
2.2 & & 35 \\
5 & & 33 \\
9.8 & & 28 \\
0 & 36 & 43 \\
2.2 & & 41 \\
5 & & 39 \\
\hline
\end{tabular}



Figure 1. Melting temperature versus epoxidation amount for solution epoxidized TPI melt crystallized at $25^{\circ} \mathrm{C}(\bigcirc)$ and at $36^{\circ} \mathrm{C}(\mathrm{O})$. 
with the degree of supercooling, which is $T_{\mathrm{m}}{ }^{*}-T_{\mathrm{c}}$. Here $T_{\mathrm{m}}^{*}$ is the equilibrium melting temperature of perticular copolymer sample. As expected, an increase in melting temperature with decreasing degree of supercooling is observed. Linear extrapolation to zero epoxidation of the melting temperature plot yields a value of $37^{\circ} \mathrm{C}$. Melting temperatures were observed as function of crystallization temperature for unepoxidized TPI. ${ }^{9}$ The values of melting temperature for unepoxidized TPI are $43^{\circ} \mathrm{C}$ for $T_{\mathrm{c}}=25^{\circ} \mathrm{C}, 43^{\circ} \mathrm{C}$ for $T_{\mathrm{c}}=36^{\circ} \mathrm{C}$ and $46^{\circ} \mathrm{C}$ for $T_{\mathrm{c}}=43^{\circ} \mathrm{C}$. When unepoxidized TPI sample at $70^{\circ} \mathrm{C}$ is cooled to $0^{\circ} \mathrm{C}$ in an ice bath and heated to $25^{\circ} \mathrm{C}$, the melting temperature is $39^{\circ} \mathrm{C}$, a value within experimental error in agreement with that found by the above mentioned extrapolation.

Melting points of solution crystallized epoxidized TPI obtained previously ${ }^{10}$ showed a different trend compared those with melt crystallized materials. There was no change in melting temperature up to $5 \%$ oxirane content. The decrease in melting temperature was apparent for $9.8 \%$ epoxidized TPI. It was concluded that no detectable epoxidized units were present in the crystal up to $5 \%$ oxirane content; there was evidence of a small number of oxirane units included in the crystal for $9.8 \%$ epoxidized TPI. Before a complete explanation is given for the different trend between solution and melt crystallized material, further study is believed necessary.

DSC data, as expected, show a melting temperature depression with increasing oxirane content. Since the lamellar thickness for the melt crystallized sample believed to be significantly less than the solution crystallized ones, presence of comonomer units in the crystal core are expected to be less. Therefore, it may be reasonable to assume that all the comonomer units are ejected from crystal core. The rejection of a comonomer unit from the crystal core during the crystallization process should also lead to the rejection of crystallizable units attached to it. These eliminate the

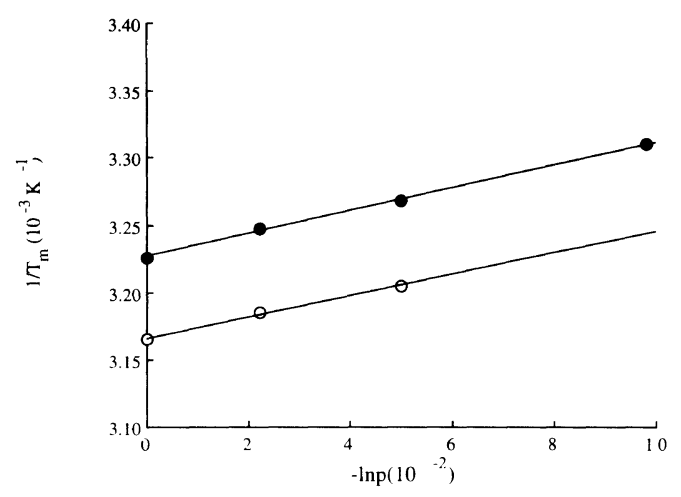

Figure 2. Melting point depression of the solution epoxidized TPI versus epoxy content. - , crystallized at $25^{\circ} \mathrm{C}$; $\mathrm{O}$, crystallized at $36^{\circ} \mathrm{C}$.

crystal growth and limit the crystallite size can be achieved. This can cause the depression in melting temperature as the oxirane content increases.

The theory for melting copolymers has been developed by Flory et al. ${ }^{11}$ at equilibrium when the comonomer is excluded from the crystal core. The dependence of the melting point on the fraction of crystallizable units in a random copolymer is given by

$$
1 / T_{\mathrm{m}}-1 / T_{\mathrm{m}}{ }^{0}=-\left(R / \Delta H_{\mathrm{f}}\right) \ln p
$$

Where $T_{\mathrm{m}}{ }^{0}$ is the melting point of homopolymer, $T_{\mathrm{m}}$ is the melting temperature of copolymer, $p$ is the fraction of TPI unit present and $\Delta H_{\mathrm{f}}$ is the heat of fusion per mole of homopolymer unit. Figure 2 shows the plot of melting temperature versus $\ln p$ at 25 and $36^{\circ} \mathrm{C}$. The slope of this plot gives a $\Delta H_{\mathrm{f}}$ value of $8.25 \mathrm{~kJ} \mathrm{~mol}^{-1}$ for pure TPI. This is in good agreement with heat of fusion $8 \mathrm{~kJ} \mathrm{~mol}^{-1}$ obtained previously. ${ }^{12}$ This implies that all the epoxy units are rejected from the crystal core during the melt crystallization at 25 and $36^{\circ} \mathrm{C}$.

\section{REFERENCES}

1. R. J. Roe and C. Gerniewski, Macromolecules, 6, 212 (1972).

2. I. R. Harrison and E. Baer, J. Polym. Sci., Polym. Phys. Ed., 9, 1305 (1971). 
3. I. R. Harrison and E. Baer, J. Polym. Soc., Polym. Phys. Ed., 9, 843 (1971).

4. A. Marchetti and E. Martuscelli, J. Polym. Sci., Polym. Phys. Ed., 14, 157 (1976).

5. P. Wang and-A. E. Woodward, Makromolecules, 20, 2718 (1987).

6. J. P. Corrigan, I. S. Zemel, and A. E. Woodward, J. Polym. Sci., B, 27, 1135 (1989).

7. I. S. Zemel, J. P. Corrigan, and A. E. Woodward, $J$. Polym. Sci., B, 27, 2479 (1989).
8. N. Vasanthan, J. P. Corrigan, and A. E. Woodward, Makromol. Chem. in press.

9. N. Vasanthan, J. P. Corrigan, and A. E. Woodward, Polymer, 34, 2270 (1993).

10. J. Xu and A. E. Woodward, Macromolecules, 21, 2994 (1988).

11. P. J. Flory, Trans. Faraday Soc., 51, 848 (1955).

12. S. Mukherji and A. E. Woodward, J. Polym. Sci., Polym. Phys. Ed., 22, 793 (1984). 